\title{
18. Progress Report of the Study of Nautilus macromphalus in Captivity*)
}

\author{
By Nobuyuki KaWAmoto \\ The Nihon University \\ (Communicated by Teiichi KobaYAshi, M. J. A., March 13, 1978)
}

Introduction. Our first experiment on rearing Nautilus macromphalus, a rare cephalopod species known as one of the living fossils, was successful in keeping the animal alive for 272 days, from the middle of June 1976 to the middle of March 1977 (Hamada 1977a; Hamada and Mikami 1977), which is the longest record of keeping Nautilus species alive in captivity. During this experiment, the water temperature was lowered gradually for the first four months and kept at about $15^{\circ} \mathrm{C}$ for the last several months. The lowering of the temperature might correspond to the migration of the animal to a deeper habitat during the hot season near the coral reefs of New Caledonia.

Three mature male and female individuals respectively often copulated during the above period, and as a result at least 22 eggs were laid in a rearing tank. Although these eggs were all infertile, many new observations were made on the reproductive behaviour as already reported in several short papers, such as the ones by Kanie, Obata and Mikami (1977), Mikami and Okutani (1977), etc. that appeared in the Annual Report of the Japanese Expert Consultation on Living Nautilus (JECOLN). Based on the results of the 9-month rearing experiment, some hypotheses on the ecological conditions of the living nautili were presented to explain the distribution of the animals in the Western Pacific and the Australian waters (Hamada 1977b; Hamada and Mikami 1977).

Some histological observations by SEM (Fukuda 1977), anatomical descriptions (Okutani and Mikami 1977), and biometrical studies (Hirano 1977) were also recently published. The results of further investigations and detailed reports will be assembled in the Memoir no. 1 of the JECOLN within this year.

The present paper deals with the 2nd rearing experiment that was commenced at the beginning of July 1977 and is still in progress.

Procedures of the 2nd experiment. Four specimens (three males and a female) were sent from the South Pacific on July 5, 1977 through the courtesy of ORSTOM, City Aquarium of Nouméa and Mr. Georges Tsutsui in New Caledonia. Unfortunately, however, three of the

*) JECOLN Contribution, no. 26 . 


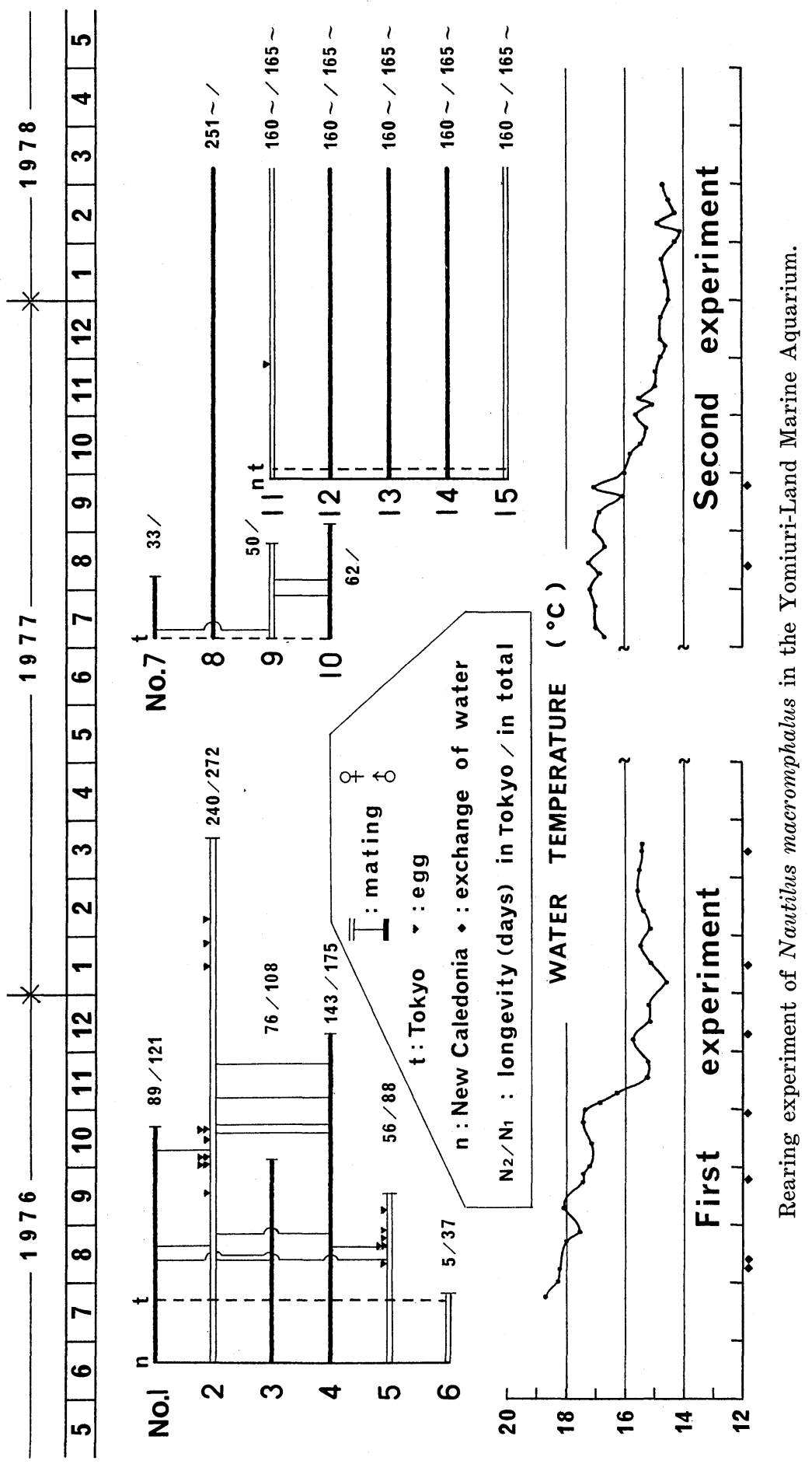


specimens died within two months after their arrival in Tokyo. Only one male (no. 8) survived and joined the newly supplied five specimens which were brought by Hamada and Mikami, the members of the JECOLN, on October 4, 1977 from New Caledonia. These five specimens were caught by the research vessel of ORSTOM "The Vauban" using a net trap for crabs at the depth of $400 \mathrm{~m}$ off the barrier reef called "Grand Recif du Sud" of New Caledonia on September 29.

Results of the 2nd experiment. Two females were included among these five specimens. As a result, four males and two females have lived together in the tank for 165 days up to March 13, 1978, as illustrated in the diagram. This mass longevity of Nautilus macromphalus in captivity is a new record again. It is noteworthy that only one egg capsule, which was furthermore abnormal, was laid during this experiment (no.11). Though a female individual no. 9 mated three times with no. 7 and no. 10 at the beginning of the 2nd experiment, they all died before spawning. In the first experiment, on the contrary, more than 22 eggs were produced after ten copulations as far as we observed. As strongly suggested by the first 9-month experiment, the main reproductive season is in the period from June to August and the subsequent spawning season is in August-October, except for an unusual reproduction in January-February that may happen under unnatural conditions in captivity.

The less frequent reproductive behaviour observed during the 2nd experiment as compared to the 1st one, may be explained in terms of seasonal periodicity possibly caused by water temperature changes. All copulations observed occurred in comparatively warm water, i.e., 17 to $19^{\circ} \mathrm{C}$ approximately. This means that in natural environment copulation may happen in fairly shallow water rather than the usual deeper and cooler habitat of the animal. Thus the presumed seasonal migration related to the reproductive behaviour of the population of Nautilus macromphalus in the New Caledonian waters (Hamada and Mikami 1977) seems to be in harmony with the data obtained by these two long-term rearing experiments.

During the first experiment we could not observe any shell increase because all the specimens used were almost full grown in size. On the contrary, the extant six specimens are in different growth stages with no. 15 being the smallest and no. 8 the largest. The measurements of the specimens are tabulated as follows: 


\begin{tabular}{c|l|c|c}
\hline Spec. no. & Sex & $\begin{array}{c}\text { Max. diam. } \\
\text { (Feb. 25) }\end{array}$ & $\begin{array}{c}\text { Amount of growth at the } \\
\text { apertural center } \\
\text { (Nov. 18-Feb. 25) }\end{array}$ \\
\hline 8 & male & $165.40 \mathrm{~mm}$ & $0.35 \mathrm{~mm}$ \\
11 & female & $150.95 \prime \prime$ & $12.55 \prime \prime$ \\
12 & male & $142.35 \prime \prime$ & $12.44 \prime \prime$ \\
13 & male & $155.05 \prime$ & $8.15 \prime \prime$ \\
14 & male & $163.35 \prime$ & $0.80 \prime \prime$ \\
15 & female & $128.90 \prime$ & $4.80 \prime \prime$ \\
\hline
\end{tabular}

Text-Figs. 1-3 illustrate some examples of the shell increments. Figs. 1a and 1b show a young female (no. 15) with a repaired margin. Fig. 2, an adult male (no. 12) with a newly formed apertural margin that is broadly covered by thin black film of organic material, and Fig. 3, a male shell (no. 8) at the gerontic stage showing neither increase of the shell nor organic cover at the apertural margin. Amounts of the shell increments are not uniform as shown above, mainly because of the various growth stages of the different specimens. However, this is the first convincing data concerning the shell growth of
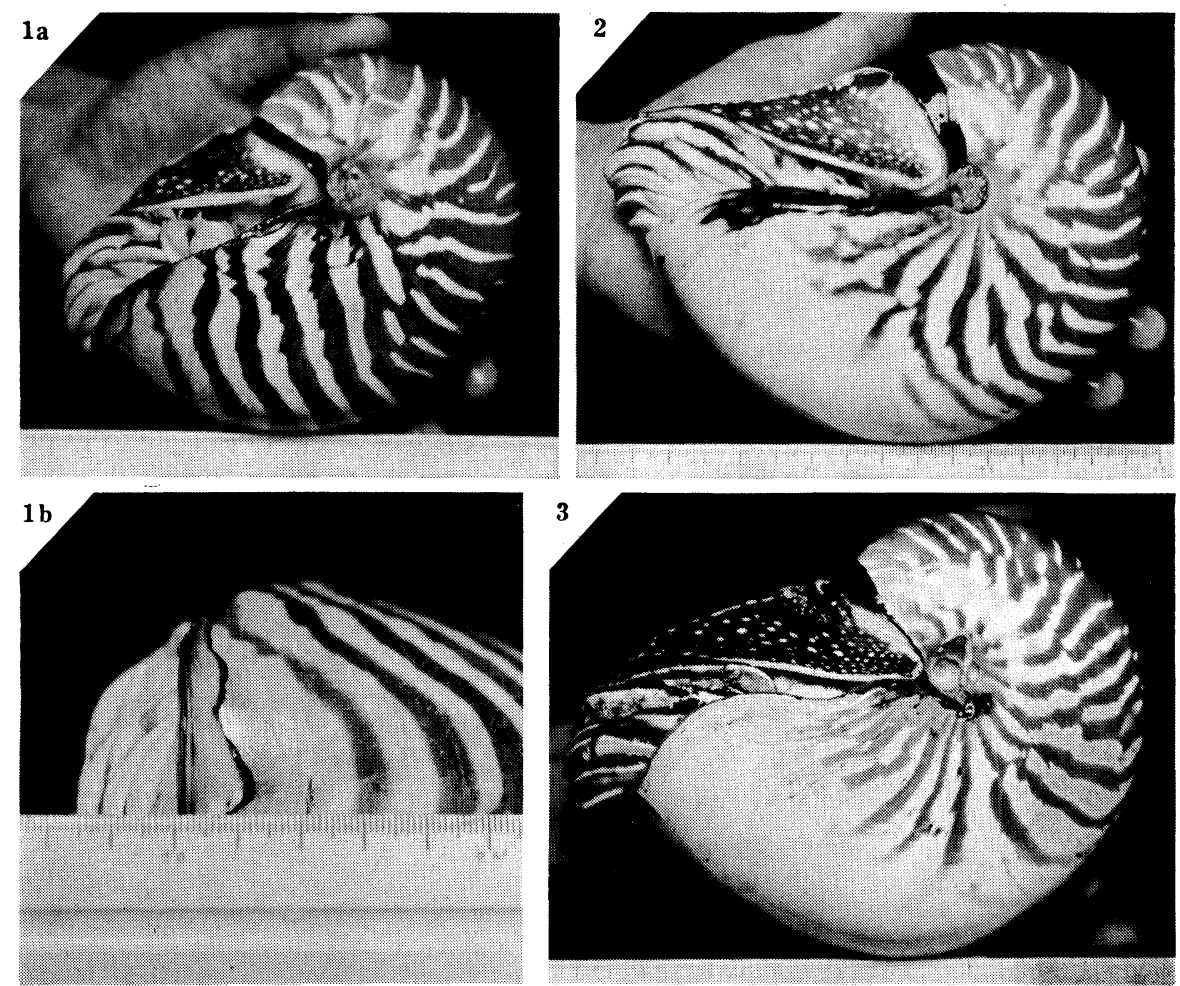

Figs. 1-3. Shell growth of Nautilus macromphalus in captivity. 
the modern Nautilus species even though it was under arbitrary conditions in captivity.

Acknowledgements. This summary report is presented on behalf of JECOLN. Members of this organization are Dr. Y. Deguchi of the Nihon University, Mr. Y. Fukuda of the Chiba Prefectural Institute of Public Health, Dr. T. Habe of the National Science Museum, Dr. T. Hamada of the University of Tokyo, Dr. H. Hirano of the Waseda University, Dr. Y. Kanie of the Yokosuka City Museum, Mr. S. Mikami of the Yomiuri-Land Marine Aquarium, Dr. I. Obata of the National Science Museum and Dr. T. Okutani of the Tokai Regional Fisheries Research Laboratory.

We wish to express our sincere thanks to the Yomiuri-Land Co. Ltd. for their kind offer of the rearing facilities. We are much indebted to Dr. Legand and Mr. Rancurel of ORSTOM in Nouméa, Mr. Magnier of the City Aquarium of Nouméa, and also to Mr. Georges Tsutsui, the Honorary Consul of Japan in New Caledonia, for their great kindness and help in obtaining the living specimens of Nautilus macromphalus used for the experiments. Special thanks are also due to the UTA French Airlines for the well organized transportation of the specimens from New Caledonia to Tokyo.

\section{References}

Fukuda, Y. (1977): The structure of sensory tentacles of Nautilus macromphalus. Marine Science Monthly, 9(5), 62-69 (in Japanese with English summary).

Hamada, T. (1977) : Renewal of the world record of Nautilus rearing in Japan. Ibid., 9(2), 62-64 (in Japanese with English summary).

- (1977b) : Distribution and some ecological barriers of modern Nautilus species. Sci. Pap. Coll. Gen. Educ., Univ. Tokyo, 27 (2), 89-102.

Hamada, T., and Mikami, S. (1977): A fundamental assumption on the habitat condition of Nautilus and its application to the rearing of $N$. macromphalus. Ibid., 27 (1) , 31-39.

Hirano, H. (1977) : Biometric characteristics of Nautilus pompilius. Sci. Research, Waseda Univ., no. 26, pp. 16-26.

Kanie, Y., Obata, I., and Mikami, S. (1977) : Some observations on Nautilus macromphalus Sowerby in breeding aquarium from paleontological points of view. Jour. Geol. Soc. Japan, 80 (4), 247-249.

Mikami, S., and Okutani, T. (1977): Preliminary observations on maneuvering, feeding, copulating and spawning behaviors of Nautilus macromphalus in captivity. Venus, 36(1), 28-41.

Okutani, T., and Mikami, S. (1977) : Description on beaks of Nautilus macromphalus Sowerby. Ibid., 36(3), 115-121. 